\title{
A NEW ANALYTICAL METHODOLOGY TO HANDLE TIME-COST TRADE-OFF PROBLEM WITH CONSIDERING QUALITY LOSS COST UNDER INTERVAL-VALUED FUZZY UNCERTAINTY
}

\author{
Mohammad Hossein HAGHIGHI ${ }^{1}$, Seyed Meysam MOUSAVI ${ }^{1^{*}}$, \\ Jurgita ANTUCHEVIČIENE ${ }^{2}$ D, Vahid MOHAGHEGHI ${ }^{1}$ \\ ${ }^{1}$ Department of Industrial Engineering, Faculty of Engineering, Shahed University, Tehran, Iran \\ ${ }^{2}$ Department of Construction Management and Real Estate, Faculty of Civil Engineering, \\ Vilnius Gediminas Technical University, Lithuania
}

Received 26 April 2018; accepted 08 August 2018

\begin{abstract}
This paper proposes a new framework in addressing time-cost trade-off problem (TCTP) under uncertainty. First critical path analysis is carried out based on developing a new intervalvalued fuzzy (IVF)-program evaluation and review technique (PERT) approach. Then, non-conformance risks that influence on execution quality of activities are identified and evaluated based on a new approach that considers probability of risk along with impacts on time, cost, and performance. Then, a new mathematical model under IVF uncertainty is presented to decrease project total time while considering time, cost and quality loss cost that is determined in form of rework or modification cost. Finally, the approach categorizes the activities in three groups based on their level of criticality. Outcome of this methodology is a scheduling that addresses time, cost and quality trade-offs in addition to categorizing activities in different groups based on being on the critical path. Therefore, the project manager not only gets a scheduling based on the TCTP with considering quality loss cost but also has a knowledge of activities that require extra attentions. To show the steps of this methodology, an existing application from the literature is adopted and solved.
\end{abstract}

Keywords: time-cost trade-off problems, quality loss cost, project non-conformance risks, intervalvalued fuzzy-program evaluation and review technique, interval-valued fuzzy sets.

JEL Classification: C02, C41, C52, D81, O22.

\section{Introduction}

Project management has a vital role in modern management. It is noted as the application of knowledge, skills, tools, and techniques in project activities to reach the project requirements (e.g., Mousavi, Tavakkoli-Moghaddam, Vahdani, Hashemi, \& Sanjari, 2013; Mousavi, Vahdani, \& Abdollahzade, 2015; Ebrahimnejad, Mousavi, Tavakkoli-Moghaddam, \& Heydar,

*Corresponding author. E-mail: sm.mousavi@shahed.ac.ir

This is an Open Access article distributed under the terms of the Creative Commons Attribution License (http://creativecommons. org/licenses/by/4.0/), which permits unrestricted use, distribution, and reproduction in any medium, provided the original author and source are credited. 
2014; Vahdani, Mousavi, Hashemi, Mousakhani, \& Ebrahimnejad, 2014). Project scheduling problems (PSPs) are highly applied in managing resources. A PSP is characterized by its activities and the denoted time for them and by the precedence relations among them. The overall purpose of project scheduling is optimizing a set of measurement functions while regarding a set of precedence and resource constraints (Singh \& Ernst, 2011; Mohagheghi, Mousavi, \& Vahdani, 2017).

Time-cost trade-off (TCT) is a very common approach applied by project managers to reach the required completion time of the projects with the least extra cost (El-Sayegh \& Al-Haj, 2017). In fact, TCT deals with modifying implementation time of project activities while doing a trade-off between the completion time and the project cost (Ke \& Ma, 2014). Time-cost trade-off problems (TCTPs) are often employed for project scheduling in situations where the project is supposed to be completed sooner than a pre-determined deadline (Bettemir \& Birgönül, 2017). This application may require additional resources. Therefore, this could lead to extra total cost of projects.

An efficient technique applied to make the overall project duration shorter is to crash project activities. Crashing is in fact a trade-off issue between cost and duration of activities to reach the maximum crashing and the minimum additional cost at the same time (Zhang \& Zhong, 2018).

Quality of each executed project activity is a significant matter in project management. If the outcome of a project fulfils the expectations of project contractors, it is known as a success (e.g., Martin \& Tate 2002; Mohagheghi, Mousavi, Vahdani, \& Shahriari, 2017; Mohagheghi, Mousavi, Vahdani, \& Siadat, 2017). In projects even if the overall project quality is satisfactory, it is possible that due to a single project activity that does not meet the project requirements, rework be required and possibly time delay and cost overruns happen.

Several approaches were introduced in addressing quality in TCTPs. Kim, Kang, and Hwang (2012) developed a new approach for project scheduling by regarding potential quality loss cost in the TCTPs. Afruzi, Najafi, Roghanian, and Mazinani (2014) presented a multiobjective approach for solving discrete time-cost-quality trade-off problems (TCQTPs) with mode-identity and resource-constrained situations. Tavana, Abtahi, and Khalili-Damghani (2014) through a multi-objective multi-mode model addressed preemptive time-cost-quality trade-off project scheduling. Z. He, H. He, Liu, and Wang (2017) applied variable neighborhood search and tabu search to handle the TCTP.

Monghasemi, Nikoo, Fasaee, and Adamowski (2015) introduced a multi-criteria decision making model for TCQTPs in construction projects. The NSGA-II procedure was used to identify Pareto optimal solutions. Salari, Bagherpour, and Reihani (2015) presented fuzzy earned value management into a TCTP and used a statistical-based approach. El-Sayegh and Al-Haj (2017) considered float loss impact for TCTPs. Tran, Luong, Duong, Le, and Pham (2017) presented a search approach for scheduling repetitive projects in time-cost-qualitywork continuity trade-off problem. Wood (2017) applied integrated stochastic and fuzzy multi-objective optimization for TCQTP in gas and oil projects. Another study on project related issues is the study of Hazır (2015), in which a review of approaches and analytical models of project control systems that focused on earned value analysis and optimization tools was presented. Cheng and Tran (2014) proposed a two-phase differential evolution model to address construction projects TCTP under resource-constrained limitations. How- 
ever, not addressing quality in their study would diminish the closeness of their method to real-world projects. H. G. Lee, Yi, and D. E. Lee (2015) presented a stochastic TCT that integrated the critical path algorithm with genetic algorithm. Their study despite its novelty did not consider issues such as risk and quality.

In projects, it is very likely for the duration and completion times of activities to be uncertain. In other words, uncertainty exists in almost every aspect of any project. Moreover, since activities are unique and historical data is often missing, it is hard for a project manager to correctly address these random variables. To properly handle this matter, the fuzzy method is often applied. $\mathrm{Xu}$, Zheng, Zeng, $\mathrm{Wu}$, and Shen (2012) proposed discrete TCTP by multiple modes with fuzzy uncertainty. Castro-Lacouture, Süer, Gonzalez-Joaqui, and Yates (2009) presented the scheduling of the TCTP with material restrictions and fuzzy sets. HosseiniNasab, Pourkheradmand, and Shahsavaripour (2017) introduced a meta-heuristic method to solve multi-mode TCQTP with trapezoidal fuzzy data.

In this paper, a new analytical methodology is presented to address TCTPs while considering quality loss cost under uncertainty. This methodology gives the project manager a better understanding of project by analyzing the activities and showing the criticality of activities. This would help avoid unpleasant surprises in projects. Moreover, the method applies the concepts of PERT, time-cost trade-off with considering quality loss cost, risk evaluation and interval-valued fuzzy sets (IVFSs) to enhance project management. In Table 1, this paper is compared with similar studies in the recent years. In addition to that, the following presents the novelties of this paper.

- A new methodology is presented that address project scheduling by considering timecost trade-off with considering quality loss cost, PERT and risk evaluation. Moreover, a trichotomic approach is used to analyse project activities.

- IVFSs are applied to address project uncertainty. These sets unlike classic sets express the degree of membership in an interval instead of a crisp value. This would be more practical in project environments (Mohagheghi et al., 2016).

- A new IVF-PERT is presented to address project scheduling. This would give a proper initial image of activities to the project manager.

- A new approach is proposed to address quality loss risk. In other words, risk is addressed through a multi-criteria analysis method instead of the common impact probability approach.

- A new mathematical model is presented to address TCTPs with considering quality loss cost. This model provides a project scheduling with crashed activities while considering additional costs and risk of quality loss.

- A trichotomic approach is developed to analyse project activities. This approach puts the activities in three groups based on their criticality. It would enhance the control of project manager on activities.

As can be seen in Table 1, in this paper a new approach of TCTP with considering quality loss cost is introduced under IVF uncertainty. Developed PERT under uncertainty for critical path analysis is carried out. Non-conformance risks for each activity are identified and calculated based on a new IVF group multi-criteria analysis that considers probability, time, cost and performance. In other words, as it can be observed in the table, this paper 
Table 1 . The novelties of this paper

\begin{tabular}{|c|c|c|c|c|c|c|c|}
\hline Research & Time & Cost & Quality & Risk & $\begin{array}{c}\text { Multi-criteria } \\
\text { analysis }\end{array}$ & $\begin{array}{l}\text { Extended } \\
\text { fuzzy } \\
\text { uncertainty }\end{array}$ & $\begin{array}{l}\text { Developed } \\
\text { PERT }\end{array}$ \\
\hline Castro-Lacouture et al. (2009) & $\star$ & * & & & & & \\
\hline Ammar (2010) & * & * & & & & & \\
\hline Chen and Tsai (2011) & * & * & & & & & \\
\hline Tavana et al. (2014) & * & * & * & & & & \\
\hline Afruzi et al. (2014) & * & * & * & & & & \\
\hline Cheng and Tran (2014) & * & * & & & & & \\
\hline Lee et al. (2015) & * & * & & & & & \\
\hline $\begin{array}{l}\text { Gwak, Son, Park, and Lee } \\
\text { (2016) }\end{array}$ & * & * & & & & & \\
\hline $\begin{array}{l}\text { Meier, Yassine, Browning, } \\
\text { and Walter (2016) }\end{array}$ & $*$ & * & & & & & \\
\hline He et al. (2017) & * & * & & & & & \\
\hline Orm and Jeunet (2018) & * & * & * & & & & \\
\hline This paper & * & * & * & * & * & * & * \\
\hline
\end{tabular}

offers a new approach that has novelty in addressing risk and quality. Moreover, the paper has novelty in applying multi-criteria analysis on this subject. Using extended fuzzy sets and applying IVF-PERT are other novel points of this paper.

The rest of this paper is organized as follows: In section 1, the proposed methodology for the TCTP with considering quality loss cost is presented. In section 2, the application of the proposed approach is depicted. To conclude the paper, final section depicts the concluding remarks of this paper.

\section{Presented methodology}

In this section, a new analytical framework is introduced that aims at addressing TCTP while considering quality loss cost in project management under uncertainty. In order to address uncertainty in time, cost and quality loss, IVFSs are used. In this process, first critical path analysis is carried out based on developing a new IVF-based PERT approach. After finding the critical path which determines the finish time of the project, non-conformance risks of activities are identified. Non-conformance risk covers any uncertainty that in case of happening could have negative impacts on cost of activities after the activity is finished (Kim, Kang, \& Hwang, 2012). After identifying the risks, they are evaluated based on a new approach that considers probability of risk along with impacts on time, cost, and performance. After evaluating activity risks, opinions of experts are used to find the number of activities that are considered in the time crashing process. This enables the approach to address managing risk in project time crashing. Then, a new mathematical model under IVF uncertainty is presented to crash project time while considering time, cost and quality loss cost trade-off that is based on Kim, Kang \& Hwang (2012) study. Finally, a trichotomic approach is used to analyze project activities. The following presents the steps of this framework (Figure 1): 
Stage 1: IVF-PERT

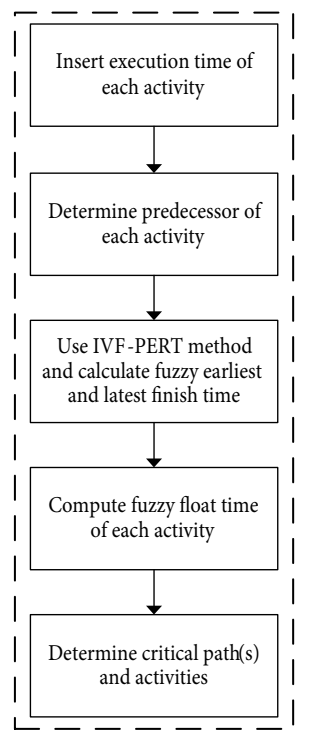

Stage 2:

Non-conformance risk

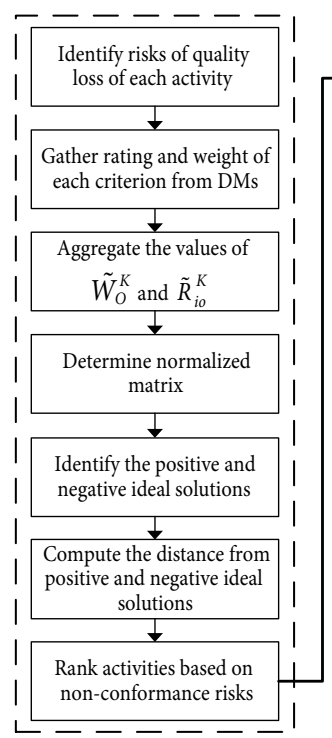

Stage 3:

Mathematical model

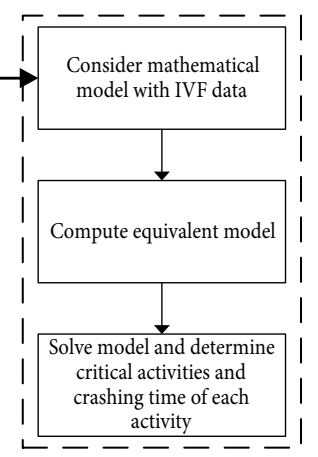

Stage 4:

Activities classification

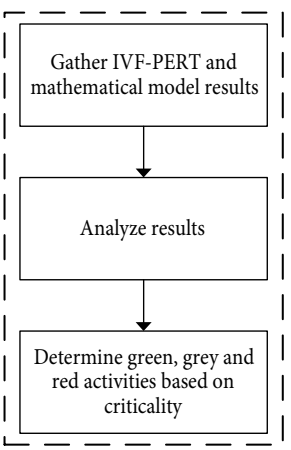

Figure 1. Proposed framework

1. Apply IVF-PERT to find the critical path(s) of project.

1.1. Use the following Eq. for each activity:

$$
\begin{aligned}
& \widetilde{E F_{i}}=\left[\left(e f_{i 1}^{u}, e f_{i 1}^{l}\right), e f_{i 2},\left(e f_{i 3}^{l}, e f_{i 3}^{u}\right)\right]=\max _{j \in \operatorname{pred}(i)}\left[\left(e f_{j 1}^{u}, e f_{j 1}^{l}\right), e f_{j 2},\left(e f_{j 3}^{l}, e f_{j 3}^{u}\right)\right]+ \\
& {\left[\left(d_{i 1}^{u}, d_{i 1}^{l}\right), d_{i 2},\left(d_{i 3}^{l}, d_{i 3}^{u}\right)\right]}
\end{aligned}
$$

where $\widetilde{E F}_{i}$ is earliest finish time of task $i, \tilde{d}_{i}$ is fuzzy duration of task $i$, and pred $(i)$ is set of activities that are immediately followed by task $i$.

For calculating of latest finish time of task $i\left(\widetilde{L F}_{i}\right)$ and fuzzy float time of task $i\left(\widetilde{f t}_{i}\right)$, the proposed method by Soltani and Haji (2007) is used.

$$
\begin{aligned}
& \widetilde{L F}_{i}=\left[\left(l f_{i 1}^{u}, l f_{i 1}^{l}\right), l f_{i 2},\left(l f_{i 3}^{l}, l f_{i 3}^{u}\right)\right] ; \\
& l f_{i 3}^{u}=\max \left(0, \min _{j \in \operatorname{succ}(i)}\left(l f_{j 3}^{u}-d_{j 3}^{u}\right)\right) ; \\
& l f_{i 3}^{l}=\max \left(0, \min \left(l f_{i 3}^{u}, \min _{j \in \operatorname{succ}(i)}\left(l f_{j 3}^{l}-d_{j 3}^{l}\right)\right) ;\right. \\
& l f_{i 2}=\max \left(0, \min \left(l f_{i 3}^{l}, \min _{j \in \operatorname{succ}(i)}\left(l f_{j 2}-d_{j 2}\right)\right) ;\right. \\
& l f_{i 1}^{l}=\max \left(0, \min \left(l f_{i 2}, \min _{j \in \operatorname{succ}(i)}\left(l f_{j 1}^{l}-d_{j 1}^{l}\right)\right) ;\right. \\
& l f_{i 1}^{u}=\max \left(0, \min \left(l f_{i 1}^{l}, \underset{j \in \operatorname{succ}(i)}{\min }\left(l f_{j 1}^{u}-d_{j 1}^{u}\right)\right) ;\right. \\
& \widetilde{f t}_{i}=\left[\left(f t_{i 1}^{u}, f t_{i 1}^{l}\right), f t_{i 2},\left(f t_{i 3}^{l}, f t_{i 3}^{u}\right)\right] ; \\
& f t_{i 3}^{u}=\max \left(0,\left(l f_{i 3}^{u}-e f_{i 3}^{u}\right)\right) ;
\end{aligned}
$$




$$
\begin{aligned}
& f t_{i 3}^{l}=\max \left(0, \min \left(f t_{i 3}^{u},\left(l f_{i 3}^{l}-e f_{i 3}^{l}\right)\right)\right) ; \\
& f t_{i 2}=\max \left(0, \min \left(f t_{i 3}^{l},\left(l f_{i 2}-e f_{i 2}\right)\right)\right) ; \\
& f t_{i 1}^{l}=\max \left(0, \min \left(f t_{i 2},\left(l f_{i 1}^{l}-e f_{i 1}^{l}\right)\right)\right) ; \\
& f t_{i 1}^{u}=\max \left(0, \min \left(f t_{i 1}^{l},\left(l f_{i 1}^{u}-e f_{i 1}^{u}\right)\right)\right),
\end{aligned}
$$

where $\operatorname{succ}(i)$ is set of activities that immediately follow activity $i$.

1.2. Determine the critical path(s). If the value of $\widetilde{f t}_{i}$ for an activity equals zero, then that activity is critical. A path that connects such activities from start node to end node is called a critical path. By crashing the time on this path, project time could get shorter.

2. Address non-conformance risk of each activity by following these steps:

2.1. Identify risks of quality loss of each activity $(i=1, \ldots, n)$.

2.2. For each activity use expert opinions to express the values of probability $\left(o_{1}\right)$, time $\left(o_{2}\right)$, cost $\left(o_{3}\right)$ and performance $\left(o_{4}\right)$ in form of linguistic variables (the decision matrix in Eq. (4)). The values denoted in Table 2 are used to express opinions, $i=1, \ldots, n ; o=1, \ldots, v$.

$$
\tilde{R}_{K}=\left(\tilde{R}_{i o}^{K}\right)_{n \times v}=\left[\begin{array}{ccc}
\tilde{R}_{11}^{K} & \cdots & \tilde{R}_{1 v}^{K} \\
\vdots & \ddots & \vdots \\
\tilde{R}_{n 1}^{K} & \cdots & \tilde{R}_{n v}^{K}
\end{array}\right] .
$$

2.3. Gather the values denoting importance of the criteria (probability, time, cost and performance) by using Table $3 \tilde{w}_{o}{ }^{k}=\left(\tilde{W}_{1}, \tilde{W}_{2}, \ldots, \tilde{W}_{v}\right), k \in T ; o=1, \ldots, v$.

Table 2. Linguistic terms for ratings

\begin{tabular}{|l|l|}
\hline \multicolumn{1}{|c|}{ Linguistic variables } & \multicolumn{1}{c|}{ IVF-numbers } \\
\hline Very poor $(\mathrm{VP}) /$ Very low(VL) & {$[(0,0), 0,(1,1.5)]$} \\
\hline Poor $(\mathrm{P}) /$ Low $(\mathrm{L})$ & {$[(0,0.5), 1,(2.5,3.5)]$} \\
\hline Moderately poor $(\mathrm{MP}) /$ Medium Low $(\mathrm{ML})$ & {$[(0,1.5), 3,(4.5,5.5)]$} \\
\hline Fair $(\mathrm{F}) /$ Medium $(\mathrm{M})$ & {$[(2.5,3.5), 5,(6.5,7.5)]$} \\
\hline Moderately good $(\mathrm{MG}) /$ Medium High $(\mathrm{MH})$ & {$[(4.5,5.5), 7,(8,8.5)]$} \\
\hline Good $(\mathrm{G}) /$ High $(\mathrm{H})$ & {$[(5.5,7.5), 9,(9.5,10)]$} \\
\hline Very Good $(\mathrm{VG}) /$ Very High $(\mathrm{VH})$ & {$[(8.5,9.5), 10,(10,10)]$} \\
\hline
\end{tabular}

Table 3. Linguistic terms for the importance weight of each criterion

\begin{tabular}{|l|l|}
\hline \multicolumn{1}{|c|}{ Linguistic variables } & \multicolumn{1}{c|}{ IVF-numbers } \\
\hline Very Low $(\mathrm{VL})$ & {$[(0,0), 0,(0.1,0.15)]$} \\
\hline Low $(\mathrm{L})$ & {$[(0,0.05), 0.1,(0.25,0.35)]$} \\
\hline Medium Low $(\mathrm{ML})$ & {$[(0,0.15), 0.3,(0.45,0.55)]$} \\
\hline Medium $(\mathrm{M})$ & {$[(0.25,0.35), 0.5,(0.65,0.75)]$} \\
\hline Medium High $(\mathrm{MH})$ & {$[(0.45,0.55), 0.7,(0.8,0.85)]$} \\
\hline High $(\mathrm{H})$ & {$[(0.55,0.75), 0.9,(0.95,1)]$} \\
\hline Very High $(\mathrm{VH})$ & {$[(0.85,0.95), 1,(1,1)]$} \\
\hline
\end{tabular}


2.4. Aggregate the values of $\tilde{w}_{o}{ }^{k}$ and $\tilde{R}_{i o}^{K}$ by computing the average value of gathered opinions.

2.5. Normalize the values denoting the rating of risks by using the following Eqs:

$$
\begin{gathered}
\tilde{G}=\left[\begin{array}{ccc}
\tilde{G}_{11} & \cdots & \tilde{G}_{1 v} \\
\vdots & \ddots & \vdots \\
\tilde{G}_{n 1} & \cdots & \tilde{G}_{n v}
\end{array}\right] ; \\
\tilde{G}_{i o}=\left[\left(\left(\frac{r_{i o 1}^{U}}{r^{\star}}\right),\left(\frac{r_{i o 1}^{L}}{r^{\star}}\right)\right),\left(\frac{r_{i o 2}}{r^{\star}}\right),\left(\left(\frac{r_{i o 3}^{L}}{r^{\star}}\right),\left(\frac{r_{i o 3}}{r^{\star}}\right)\right)\right] i=1,2, \ldots, n, o \in B E ; \\
\tilde{G}_{i o}=\left[\left(\left(\frac{r^{-}}{r_{i o 3}^{U}}\right),\left(\frac{r^{-}}{r_{i o 3}^{L}}\right)\right),\left(\frac{r^{-}}{r_{i o 2}}\right),\left(\left(\frac{r^{-}}{r_{i o 1}^{L}}\right),\left(\frac{r^{-}}{r_{i o 1}^{U}}\right)\right)\right] i=1,2, \ldots, n, o \in C O,
\end{gathered}
$$

where $B E$ denotes the set of benefit criteria and $C O$ represents the set of cost criteria. $r$ * and $r^{-}$are also obtained as presented in Eqs (8) and (9):

$$
\begin{aligned}
& r^{\star}=\max _{i}\left(r_{i o}\right)_{3}^{U} ; \\
& r^{-}=\min _{i}\left(r_{i o}\right)_{1}^{U} .
\end{aligned}
$$

2.6. Multiply the value of ratings in values of criteria importance to make the weighted decision matrix.

$\tilde{F}_{i o}=\tilde{G}_{i o} \times \tilde{w}_{o}=$

$$
\tilde{F}=\left[\begin{array}{ccc}
\tilde{F}_{11} & \cdots & \tilde{F}_{1 v} \\
\vdots & \ddots & \vdots \\
\tilde{F}_{n 1} & \cdots & \tilde{F}_{n v}
\end{array}\right]
$$

$$
\left[\left(\left(g_{i o}\right)_{1}^{U} \times\left(w_{o}\right)_{1}^{U},\left(g_{i o}\right)_{1}^{L} \times\left(w_{o}\right)_{1}^{L}\right),\left(g_{\text {io }}\right)_{2} \times\left(w_{o}\right)_{2},\left(\left(g_{\text {io }}\right)_{3}^{L} \times\left(w_{o}\right)_{3}^{L},\left(g_{\text {io }}\right)_{3}^{U} \times\left(w_{o}\right)_{3}^{U}\right)\right] .
$$

2.7. Identify the positive and negative ideal solutions as $[(1,1), 1,(1,1)]$ and $[(0,0), 0,(0,0)]$, respectively.

2.8. Compute the distance of each judgment from ideal solutions by using the following:

$$
\begin{aligned}
& d_{i}^{+}=\sum_{o=1}^{v} \sqrt{\frac{1}{6} \sum_{p=1}^{3}\left(\left(f_{\text {iop }}^{U}-1\right)^{2}+\left(f_{\text {iop }}^{L}-1\right)^{2}\right)}, i=1,2, \ldots, n ; \\
& d^{-}{ }_{i}=\sum_{o=1}^{v} \sqrt{\frac{1}{6} \sum_{p=1}^{3}\left(\left(f_{i o p}^{U}-0\right)^{2}+\left(f_{i o p}^{L}-0\right)^{2}\right)}, i=1,2, \ldots, n .
\end{aligned}
$$

2.9. Use the following to compute the risk score (RS):

$$
R S_{i}=\left(\frac{d_{i}^{-}}{d_{i}^{-}+d_{i}^{+}}\right), i=1,2, \ldots, n .
$$

2.10. Rank the activities based on RS. 
3. Use the following model to crash project duration while considering risk of quality loss. Variables of the presented model are $z_{j}$ that are decision variables denoting if activity $j$ is selected as non-conformance risk activity 1 , otherwise 0 , crash time for the completion of activity $j\left(y_{j}\right)$, and start time of activity $j\left(x_{j}\right)$.

3.1. Gather the data required for solving the model. Parameters of the presented model are direct cost per unit time for activity $j\left(m_{j}\right)$ that is calculated based on normal direct cost of activity $j\left(c_{j}\right)$, crashed direct cost of activity $j\left(c_{j}^{\prime}\right)$, normal completion time for activity $j\left(n c_{j}\right)$, crashed completion time for activity $j\left(c c_{j}\right)$. Another parameters of the model are maximum reduced time for activity $j\left(R_{j}\right)$, normal completion time for last activity $\left(n c_{n}\right)$, due time of project $(D)$, coefficients given by DMs ( $\alpha$ and $\beta$ ), arbitrarily large number $(P)$, and number of activities $(N)$.

Quality loss cost of activity $j\left(q l c_{j}\right)$ is determined by DM and is equal to: $q l c_{j}=\alpha \cdot c_{j}^{\prime}$

$\alpha_{1} \in[1, \infty)$ quality loss cost (i.e., rework and modification cost) is more than crashed direct cost;

$\alpha_{2}=1$ quality loss cost is equal with crashed direct cost;

$\alpha_{3} \in[0,1)$ quality loss cost is lower than crashed direct cost.

3.2. Form the following model to crash the duration of project while minimizing the cost of crashing and quality loss cost.

$$
\min \sum_{j=1}^{n}\left[\left(m_{j 1}^{u}, m_{j 1}^{l}\right), m_{j 2},\left(m_{j 3}^{l}, m_{j 3}^{u}\right)\right] y_{j}+\sum_{j=1}^{n}\left[\left(q l c_{j 1}^{u}, q l c_{j 1}^{l}\right), q l c_{j 2},\left(q l c_{j 3}^{l}, q l c_{j 3}^{u}\right)\right] z_{j}
$$

Subject to:

$$
\begin{aligned}
& Y_{j} \leq\left[\left(R_{j 1}^{u}, R_{j 1}^{l}\right), R_{j 2},\left(R_{j 3}^{l}, R_{j 3}^{u}\right)\right], \text { for all } j ; \\
& x_{j} \geq x_{i}+\left(\left[\left(n c_{i 1}^{u}, n c_{i 1}^{l}\right), n c_{i 2},\left(n c_{i 3}^{l}, n c_{i 3}^{u}\right)\right]-Y_{i}\right) i \in \operatorname{pred}(j) ; \\
& x_{n}+\left(\left[\left(n c_{n 1}^{u}, n c_{n 1}^{l}\right), n c_{n 2},\left(n c_{n 3}^{l}, n c_{n 3}^{u}\right)\right]-Y_{n}\right) \leq\left[\left(D_{1}^{u}, D_{1}^{l}\right), D_{2},\left(D_{3}^{l}, D_{3}^{u}\right)\right] ; \\
& N^{\star} \alpha \leq \sum_{j=1}^{n} Z_{j} \leq N^{\star} \beta ; \\
& p Y_{j} \geq Z_{j}, \text { for all } j ; \\
& \alpha \leq \beta ; \\
& Z_{j} \in\{1,0\}, \text { for all } j ; \\
& Y_{j} \geq 0, \text { for all } j .
\end{aligned}
$$

Eq. (16) indicates that the time of each activity cannot only be reduced more than its maximum time reduction. Eq. (17) shows that start time of each activity should be as big as finish time of all immediate predecessors. Eq. (18) indicates that the project cannot be finished after its due date. The due date is stated by the decision makers (DMs). Eq. (19) states that the number of non-conformance risk activities is limited to a lower and up- 
per value decided by the DM. Eq. (20) indicates that non-conformance risk activities is bounded by crash time.

3.3. Solve the crisp equivalent model presented in (24)-(32). In order to solve the model, the expected value of IVF values are used. The equivalent crisp model is presented in the following:

$$
\min \sum_{j=1}^{n}\left(m_{j 2}+\frac{m_{j 3}^{l}-m_{j 1}^{l}}{12}+\frac{m_{j 3}^{u}-m_{j 1}^{u}}{12}\right) y_{j}+\sum_{j=1}^{n}\left(q l c_{j 2}+\frac{q l c_{j 3}^{L}-q l c_{j 1}^{L}}{12}+\frac{q l c_{j 3}^{U}-q l c_{j 1}^{U}}{12}\right) z_{j}
$$

Subject to:

$$
\begin{aligned}
& Y_{j} \leq\left(R_{j 2}+\frac{R_{j 3}^{l}-R_{j 1}^{l}}{12}+\frac{R_{j 3}^{u}-R_{j 1}^{u}}{12}\right), \text { for all } j ; \\
& x_{j} \geq x_{i}+\left(\left(n c_{i 2}+\frac{n c_{i 3}^{L}-n c_{i 1}^{L}}{12}+\frac{n c_{i 3}^{U}-n c_{i 1}^{U}}{12}\right)-Y_{i}\right) i \in \operatorname{pred}(j) ; \\
& x_{n}+\left(\left(n c_{n 2}+\frac{n c_{n 3}^{L}-n c_{n 1}^{L}}{12}+\frac{n c_{n 3}^{U}-n c_{n 1}^{U}}{12}\right)-Y_{n}\right) \leq\left(D_{2}+\frac{D_{3}^{L}-D_{1}^{L}}{12}+\frac{D_{3}^{U}-D_{1}^{U}}{12}\right) ; \\
& N^{*} \alpha \leq \sum_{j=1}^{n} Z_{j} \leq N^{\star} \beta ; \\
& p Y_{j} \geq Z_{j}, \text { for all } j ; \\
& \alpha \leq \beta ; \\
& Z_{j} \in\{1,0\}, \text { for all } j ; \\
& Y_{j} \geq 0, \text { for all } j .
\end{aligned}
$$

4. Analyze the activities by using the trichotomic approach. In this step, the activities are grouped in three parts. First group denoted as green shows the activities that are not on the critical path in the PERT and the crashed scheduling. The second group denoted as grey are the activities that are on the critical path only in one of the scheduling yielded in steps 1 and 3. Finally, red group denotes the activities that are on the critical paths achieved by steps 1 and 3. These activities require more attention since they are critical in completing the project on the stated date, cost and quality. The activities are depicted in the form of Figure 2. This image could provide the project manager with a proper understanding of activities.

\begin{tabular}{|c|c|c|}
\hline Activity 1 & Activity 1 & Activity 1 \\
\hline Activity 2 & Activity 2 & Activity 2 \\
\hline$\ldots$ & $\ldots$ & $\ldots$ \\
\hline Activity $\mathrm{j}$ & Activity $\mathrm{j}$ & Activity $\mathrm{j}$ \\
\hline
\end{tabular}

Figure 2. Activities analysis based on their criticality 


\section{Application}

To present the application of the proposed framework, in this section, an application presented in the study of Kim et al. (2012) is adopted and solved. A project is supposed to be over in 19 days. A project manager is chosen to lead the project. The project manager is looking forward to crash activities while taking the project in the budget limits and minimizing quality loss cost for activities. The data related to the TCTP is presented in Table 4. Moreover, an activity on node (AON) diagram is presented to depict the relationship among activities. Figure 3 presents this AON diagram.

Table 4. Data presenting the features of project activities

\begin{tabular}{|c|c|c|c|c|c|}
\hline 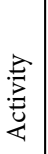 & 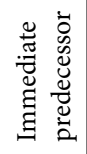 & $N C_{j}$ (days) & $C_{j} 100 \$$ & $C C_{j}$ (days) & $C_{j}^{\prime} 100 \$$ \\
\hline A & - & $((2.25,2.5), 3,(3.5,3.75))$ & $((7.1,12.5), 17.8,(23.4,28.6))$ & $((1,1.4), 2,(2.6,3))$ & $((10,16), 20.1,(24.1,30.1))$ \\
\hline B & A & $((2.25,2.5), 3,(3.5,3.75))$ & $((16.6,29.1), 41.7,(54.2,66.7))$ & $((0.75,1.05), 1.5,(1.95,2.35))$ & $((22.1,35.4), 44.3,(57.1,69.4))$ \\
\hline $\mathrm{C}$ & $\mathrm{A}$ & $((3.25,3.5), 4,(4.5,4.75))$ & $((27.7,48.5), 69.4,(90.2,111))$ & $((1,1.4), 2,(2.6,3))$ & $((44.6,71.4), 89.3,(107.2,134))$ \\
\hline $\mathrm{D}$ & A & $((3.25,3.5), 4,(4.5,4.75))$ & $((26.3,46.1), 65.9,(85.7,105.5))$ & $((1,1.4), 2,(2.6,3))$ & $((42.2,67.6), 84.5,(101.4,126.8))$ \\
\hline $\mathrm{E}$ & B & $((2.25,2.5), 3,(3.5,3.75))$ & $((55.2,96.6), 138.1,(179.5,220.9))$ & $((1,1.4), 2,(2.6,3))$ & $((85,136), 170,(204,255))$ \\
\hline $\mathrm{F}$ & $\mathrm{C}$ & $((1.25,1.5), 2,(2.5,2.75))$ & $((131.5,230.1), 328.8,(427.4,526))$ & $((1,1.4), 1.9,(2.4,2.65))$ & $((215.5,344.9), 431.1,(517.3,646.7))$ \\
\hline G & $\mathrm{D}$ & $((2.25,2.5), 3,(3.5,3.75))$ & $((76,133), 190,(247,304))$ & $((1,1.4), 2,(2.6,3))$ & $((105.1,168.1), 210.2,(252.2,315.3))$ \\
\hline $\mathrm{H}$ & $\mathrm{E}$ & $((0.75,1), 1.5,(2,2.25))$ & $((11.2,19.7), 28.1,(36.5,45))$ & $((0.5,0.7), 1,(1.3,1.5))$ & $((19.14,30.6), 38.29,(45.94,57.43))$ \\
\hline I & $\mathrm{F}$ & $((1.25,1.5), 2,(2.5,2.75))$ & $((6.7,11.7), 16.8,(21.8,26.9))$ & $((0.5,0.7), 1,(1.3,1.5))$ & $((11,17.6), 22,(26.4,33.1))$ \\
\hline $\mathrm{J}$ & G & $((0.75,1), 1.5,(2,2.25))$ & $((31.9,55.9), 79.8,(103.8,127.7))$ & $((0.5,0.7), 1,(1.3,1.5))$ & $((46.2,74), 92.5,(111,138.8))$ \\
\hline K & $\mathrm{H}$ & $((5.25,5.5), 6,(6.5,6.75))$ & $((49.5,86.7), 123.8,(161,198.1))$ & $((1.5,2.1), 3,(3.9,4.5))$ & $((83.6,133.9), 167.3,(200.8,251))$ \\
\hline $\mathrm{L}$ & I & $((1.25,1.5), 2,(2.5,2.75))$ & $((25,43.8), 62.6,(81.4,100.2))$ & $((0.75,1.05), 1.5,(1.95,2.25))$ & $((37.4,59.9), 74.9,(89.9,112.3))$ \\
\hline M & $\mathrm{J}$ & $((3.25,3.5), 4,(4.5,4.75))$ & $((250.3,438.1), 625.9,(813.7,1001.4))$ & $((1,1.4), 2,(2.6,3))$ & $((327.9,524.6), 655.8,(840,1050))$ \\
\hline $\mathrm{N}$ & M & $((2.25,2.5), 3,(3.5,3.75))$ & $((20.7,36.37), 51.9,(67.5,83.1))$ & $((0.5,0.7), 1,(1.3,1.5))$ & $((35.9,57.4), 71.8,(86.2,107.7))$ \\
\hline $\mathrm{O}$ & $\mathrm{N}$ & $((1.25,1.5), 2,(2.5,2.75))$ & $((5.9,10.4), 14.9,(19.3,23.8))$ & $((0.75,1.05), 1.5,(1.95,2.25))$ & $((10,16), 20.1,(24.1,30.1))$ \\
\hline $\mathrm{P}$ & $\mathrm{K}, \mathrm{L}, \mathrm{O}$ & $((1.25,1.5), 2,(2.5,2.75))$ & $((14.3,25), 35.7,(46.4,57.2))$ & $((0.5,0.7), 1,(1.3,1.5))$ & $((21.97,35.1), 43.9,(52.7,65.9))$ \\
\hline Q & $\mathrm{P}$ & $((1.25,1.5), 2,(2.5,2.75))$ & $((23.9,41.9), 59.8,(77.8,95.8))$ & $((0.75,1.05), 1.5,(1.95,2.25))$ & $((38.4,61.5), 76.9,(92.3,115.4))$ \\
\hline $\mathrm{R}$ & Q & $((0.75,1), 1.5,(2,2.25))$ & $((16.2,28.4), 40.6,(52.7,64.9))$ & $((0.5,0.7), 1,(1.3,1.5))$ & $((25.6,41), 51.3,(61.6,77))$ \\
\hline
\end{tabular}

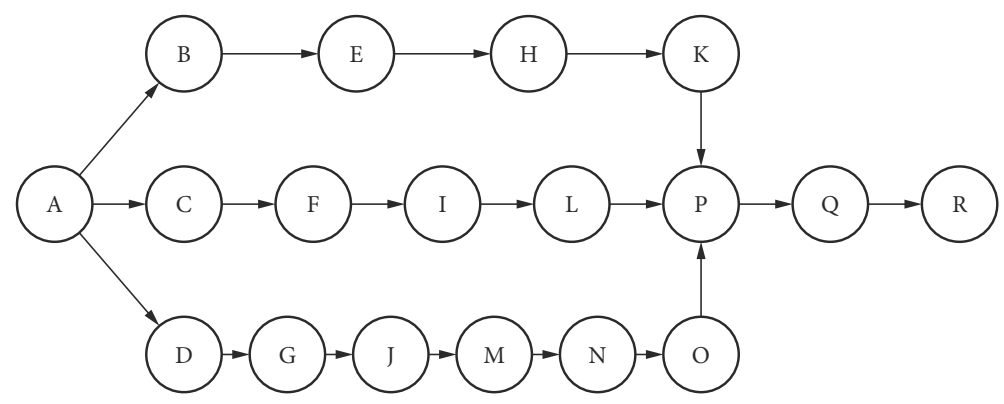

Figure 3. Project network (Kim et al., 2012) 
First, IVF-PERT is used to obtain the critical path of the project. Table 5 presents the results. The results of this step are used to obtain the critical path of the project. Critical path regards the longest time for the completion of the project and has the least level of flexibility. In this project, path 3 is the critical path.

Table 5. Length of project paths

\begin{tabular}{|c|c|}
\hline Path & IVF path length (days) \\
\hline 1. A-B-E-H-K-P-Q-R & $((16,18), 22,(26,28))$ \\
\hline 2. A-C-F-I-L-P-Q-R & $((12.5,14.5), 18.5,(22.5,24.5))$ \\
\hline 3. A-D-G-J-M-N-O-P-Q-R & $((18.5,21), 26,(31,33.5))$ \\
\hline
\end{tabular}

Earliest and latest finish time and float time for each activity is computed by using Eqs (1-3) and is presented in Table 6.

Table 6. Earliest and latest finish time and float time for each activity

\begin{tabular}{|c|c|c|c|}
\hline Activity & EF & LF & FT \\
\hline A & $((2.25,2.5), 3,(3.5,3.75))$ & $((2.25,2.5), 3,(3.5,3.75))$ & $((0,0), 0,(0,0))$ \\
\hline B & $((4.5,5), 6,(7,7.5))$ & $((7,8), 10,(12,13))$ & $((2.5,3), 4,(5,5.5))$ \\
\hline C & $((5.5,6), 7,(8,8.5))$ & $((11.5,12.5), 14.5,(16.5,17.5))$ & $((6,6.5), 7.5,(8.5,9))$ \\
\hline D & $((5.5,6), 7,(8,8.5))$ & $((5.5,6), 7,(8,8.5))$ & $((0,0), 0,(0,0))$ \\
\hline E & $((6.75,7.5), 9,(10.5,11.25))$ & $((9.25,10.5), 13,(15.5,16.75))$ & $((2.5,3), 4,(5,5.5))$ \\
\hline F & $((6.75,7.5), 9,(10.5,11.25))$ & $((12.75,14), 16.5,(19,20.25))$ & $((6,6.5), 7.5,(8.5,9))$ \\
\hline G & $((7.75,8.5), 10,(11.5,12.25))$ & $((7.75,8.5), 10,(11.5,12.25))$ & $((0,0), 0,(0,0))$ \\
\hline H & $((7.5,8.5), 10.5,(12.5,13.5))$ & $((10,11.5), 14.5,(17.5,19))$ & $((2.5,3), 4,(5,5.5))$ \\
\hline I & $((8,9), 11,(13,14))$ & $((14,15.5), 18.5,(21.5,23))$ & $((6,6.5), 7.5,(8.5,9))$ \\
\hline J & $((8.5,9.5), 11.5,(13.5,14.5))$ & $((8.5,9.5), 11.5,(13.5,14.5))$ & $((0,0), 0,(0,0))$ \\
\hline K & $((12.75,14), 16.5,(19,20.25))$ & $((15.25,17), 20.5,(24,25.75))$ & $((2.5,3), 4,5,5.5))$ \\
\hline L & $((9.25,10.5), 13,(15.5,16.75))$ & $((15.25,17), 20.5,(24,25.75))$ & $((6,6.5), 7.5,(8.5,9))$ \\
\hline M & $((11.75,13), 15.5,(18,19.25))$ & $((11.75,13), 15.5,(18,19.25))$ & $((0,0), 0,(0,0))$ \\
\hline N & $((14,15.5), 18.5,(21.5,23))$ & $((14,15.5), 18.5,(21.5,23))$ & $((0,0), 0,(0,0))$ \\
\hline O & $((15.25,17), 20.5,(24,25.75))$ & $((15.25,17), 20.5,(24,25.75))$ & $((0,0), 0,(0,0))$ \\
\hline P & $((16.5,18.5), 22.5,(26.5,28.5))$ & $((16.5,18.5), 22.5,(26.5,28.5))$ & $((0,0), 0,(0,0))$ \\
\hline Q & $((17.75,20), 24.5,(29,31.25))$ & $((17.75,20), 24.5,(29,31.25))$ & $((0,0), 0,(0,0))$ \\
\hline R & $((18.5,21), 26,(31,33.5))$ & $((18.5,21), 26,(31,33.5))$ & $((0,0), 0,(0,0))$ \\
\hline
\end{tabular}

To address quality in the presented time-cost trade-off approach, it is necessary to evaluate non-conformance risks of each activity. Therefore, the following steps are carried out:

Risk of quality loss of each activity is identified. Table 7 presents a list of identified risks. 
Table 7. Risk of each activity (Kim et al., 2012)

\begin{tabular}{|c|l|}
\hline Activity & \multicolumn{1}{|c|}{ Description of risk } \\
\hline A & Problems related to floor like uneven, contaminated and low hardness of concrete floor \\
\hline B & Wiring issues such as reverse wiring, poor contact of terminal blocks \\
\hline C & Cables loosened, poor contact of terminal blocks \\
\hline D & Touch of flexible cables while moving robot arm, interior wiring error of robot cables \\
\hline E & Broken terminal blocks inside panel \\
\hline F & Broken terminal blocks inside electrical panel, inflow of dust into electrical panel \\
\hline G & $\begin{array}{l}\text { Broken terminal blocks inside of electrical panel, leakage of electricity caused by } \\
\text { accumulated dust }\end{array}$ \\
\hline H & Conveyor chains problems, issues with automatic reject system \\
\hline I & Malfunction of wrapper-lifting system, uneven space between wrapping arm and boxes \\
\hline J & Level error of suction disks, inaccurate position where robot arm takes up box \\
\hline K & Loose bolts of supports for conveyor installation \\
\hline L & Level error of magazine stand, issues caused by pallet release from magazine stand \\
\hline M & Programming error, technical location \\
\hline N & Trouble in data processing system, preparing backup files \\
\hline O & Inoperative box counter, test run data collection for long periods of time \\
\hline P & Issues with oil pressure or pneumatic brakes \\
\hline Q & Loose cable connection, issues with interlocking systems \\
\hline R & Faulty connection, poor contact of safety devices \\
\hline
\end{tabular}

After identifying risks of each activity, the risks are evaluated based on experts' judgments while considering probability $\left(o_{1}\right)$, time $\left(o_{2}\right)$, cost $\left(o_{3}\right)$ and performance $\left(o_{4}\right)$. It should be noted that all the criteria belong to cost criteria. Moreover, importance of the criteria (probability, time, cost and performance) are evaluated by using Table 3. Tables 8 and 9 present the values for risk evaluation and criteria evaluation, respectively.

Table 8. Risk evaluation of each activity

\begin{tabular}{|c|c|c|c|c|}
\hline Activity & Probability $\left(\mathrm{O}_{1}\right)$ & Time $\left(\mathrm{O}_{2}\right)$ & Cost $\left(\mathrm{O}_{3}\right)$ & Performance $\left(\mathrm{O}_{4}\right)$ \\
\hline \multirow{4}{*}{ A } & $\mathrm{VG}$ & $\mathrm{VG}$ & $\mathrm{VG}$ & $\mathrm{G}$ \\
\cline { 2 - 5 } & $\mathrm{VG}$ & $\mathrm{G}$ & $\mathrm{VG}$ & $\mathrm{VG}$ \\
\cline { 2 - 5 } & $\mathrm{G}$ & $\mathrm{G}$ & $\mathrm{VG}$ & $\mathrm{F}$ \\
\hline \multirow{3}{*}{$\mathrm{B}$} & $\mathrm{MP}$ & $\mathrm{F}$ & $\mathrm{F}$ & $\mathrm{G}$ \\
\cline { 2 - 5 } & $\mathrm{MG}$ & $\mathrm{MG}$ & $\mathrm{F}$ & $\mathrm{G}$ \\
\cline { 2 - 5 } & $\mathrm{F}$ & $\mathrm{MP}$ & $\mathrm{MG}$ & $\mathrm{MG}$ \\
\hline \multirow{3}{*}{$\mathrm{C}$} & $\mathrm{P}$ & $\mathrm{MG}$ & $\mathrm{G}$ & $\mathrm{F}$ \\
\cline { 2 - 5 } & $\mathrm{F}$ & $\mathrm{MG}$ & $\mathrm{G}$ & $\mathrm{MG}$ \\
\cline { 2 - 5 } & $\mathrm{MG}$ & $\mathrm{MG}$ & $\mathrm{G}$ & $\mathrm{F}$ \\
\hline \multirow{3}{*}{$\mathrm{D}$} & $\mathrm{MG}$ & $\mathrm{VG}$ & $\mathrm{VG}$ & $\mathrm{MG}$ \\
\cline { 2 - 5 } & $\mathrm{VG}$ & $\mathrm{G}$ & $\mathrm{MG}$ & $\mathrm{G}$ \\
\cline { 2 - 5 } & $\mathrm{MG}$ & & & MG \\
\hline
\end{tabular}


End of Table 8

\begin{tabular}{|c|c|c|c|c|}
\hline Activity & Probability $\left(\mathrm{O}_{1}\right)$ & Time $\left(\mathrm{O}_{2}\right)$ & Cost $\left(\mathrm{O}_{3}\right)$ & Performance $\left(\mathrm{O}_{4}\right)$ \\
\hline \multirow{3}{*}{ E } & $F$ & $\mathrm{G}$ & $\mathrm{G}$ & MP \\
\hline & MG & MG & MG & MG \\
\hline & $\bar{F}$ & $\mathrm{~F}$ & $\mathrm{G}$ & $\mathrm{F}$ \\
\hline \multirow{3}{*}{$\mathrm{F}$} & MG & $\mathrm{F}$ & $\mathrm{F}$ & MG \\
\hline & MG & $\mathrm{F}$ & MG & $\mathrm{G}$ \\
\hline & $\mathrm{G}$ & MG & MP & MG \\
\hline \multirow{3}{*}{ G } & G & VG & G & G \\
\hline & VG & VG & VG & $\mathrm{VG}$ \\
\hline & $\mathrm{G}$ & $\mathrm{G}$ & VG & $\mathrm{G}$ \\
\hline \multirow{3}{*}{$\mathrm{H}$} & MP & G & MP & VG \\
\hline & $\mathrm{G}$ & $\mathrm{VG}$ & MP & $\mathrm{G}$ \\
\hline & MG & G & MG & G \\
\hline \multirow{3}{*}{ I } & VG & MG & $\mathrm{G}$ & MG \\
\hline & G & $\mathrm{F}$ & $\mathrm{F}$ & G \\
\hline & G & $\mathrm{F}$ & MG & VG \\
\hline \multirow{3}{*}{$\mathrm{J}$} & $G$ & $G$ & $\mathrm{G}$ & MG \\
\hline & $\mathrm{G}$ & MG & G & $\mathrm{G}$ \\
\hline & MG & MG & G & MG \\
\hline \multirow{3}{*}{ K } & MG & MG & MG & MP \\
\hline & $\mathrm{F}$ & MG & MG & MG \\
\hline & MG & MG & $\mathrm{F}$ & MG \\
\hline \multirow{3}{*}{$\mathrm{L}$} & $\mathrm{F}$ & MP & $\mathrm{F}$ & $\mathrm{F}$ \\
\hline & $\mathrm{F}$ & MG & G & MG \\
\hline & $\mathrm{G}$ & MG & $\mathrm{F}$ & MG \\
\hline \multirow{3}{*}{$\mathrm{M}$} & $\mathrm{F}$ & $\mathrm{F}$ & $\mathrm{F}$ & $\mathrm{F}$ \\
\hline & $F$ & MG & $F$ & $F$ \\
\hline & MG & $\mathrm{F}$ & MG & $\mathrm{F}$ \\
\hline \multirow{3}{*}{$\mathrm{N}$} & $\mathrm{F}$ & $\mathrm{F}$ & $\mathrm{F}$ & $\mathrm{F}$ \\
\hline & MP & $\mathrm{F}$ & MP & MP \\
\hline & MG & $\mathrm{F}$ & $\mathrm{F}$ & $\mathrm{F}$ \\
\hline \multirow{3}{*}{$\mathrm{O}$} & $\mathrm{F}$ & $\mathrm{F}$ & $\mathrm{F}$ & $\mathrm{F}$ \\
\hline & MP & MP & $\mathrm{P}$ & MP \\
\hline & $\mathrm{P}$ & MP & $\mathrm{P}$ & $\mathrm{P}$ \\
\hline \multirow{3}{*}{$\mathrm{P}$} & $\mathrm{F}$ & MG & $F$ & $F$ \\
\hline & G & G & $\mathrm{G}$ & G \\
\hline & $\mathrm{F}$ & $\mathrm{F}$ & MG & $\mathrm{F}$ \\
\hline \multirow{3}{*}{ Q } & $\mathrm{F}$ & $\mathrm{F}$ & $F$ & $\mathrm{~F}$ \\
\hline & MG & MG & MG & $\mathrm{F}$ \\
\hline & $\mathrm{F}$ & MG & $\mathrm{F}$ & $F$ \\
\hline \multirow{3}{*}{$\mathrm{R}$} & $\mathrm{F}$ & $\mathrm{F}$ & $\mathrm{F}$ & $\mathrm{F}$ \\
\hline & $\mathrm{P}$ & $\mathrm{P}$ & $\mathrm{P}$ & MP \\
\hline & $P$ & MP & $\mathrm{P}$ & $\mathrm{P}$ \\
\hline
\end{tabular}


Table 9. Criteria evaluation

\begin{tabular}{|c|c|c|c|c|}
\hline Criteria & Probability $\left(\mathrm{O}_{1}\right)$ & Time $\left(\mathrm{O}_{2}\right)$ & Cost $\left(\mathrm{O}_{3}\right)$ & Performance $\left(\mathrm{O}_{4}\right)$ \\
\hline DM1 & $\mathrm{VH}$ & $\mathrm{H}$ & $\mathrm{MH}$ & $\mathrm{MH}$ \\
\hline DM2 & $\mathrm{VH}$ & $\mathrm{MH}$ & $\mathrm{ML}$ & $\mathrm{M}$ \\
\hline DM3 & $\mathrm{H}$ & $\mathrm{MH}$ & $\mathrm{ML}$ & $\mathrm{M}$ \\
\hline
\end{tabular}

The gathered values are normalized by using Eqs (5-7). Normalized results are depicted in Table 10.

Table 10. Normalized risk evaluation

\begin{tabular}{|c|c|c|c|c|}
\hline 离 & Probability $\left(\mathrm{O}_{1}\right)$ & Time $\left(\mathrm{O}_{2}\right)$ & Cost $\left(\mathrm{O}_{3}\right)$ & Performance $\left(\mathrm{O}_{4}\right)$ \\
\hline A & $((0.083,0.085), 0.086,(0.094,0.111))$ & $((0.083,0.086), 0.089,(0.102,0.128))$ & $((0.083,0.083), 0.083,(0.088,0.098))$ & $((0.083,0.086), 0.089,(0.102,0.128))$ \\
\hline $\mathrm{B}$ & $((0.116,0.132), 0.167,(0.238,0.357))$ & $((0.102,0.111), 0.132,(0.172,0.217))$ & $((0.111,0.128), 0.167,(0.238,0.333))$ & $((0.088,0.093), 0.1,(0.122,0.161))$ \\
\hline $\mathrm{C}$ & $((0.128,0.147), 0.192,(0.263,0.357))$ & $((0.111,0.122), 0.147,(0.2,0.278))$ & $((0.088,0.093), 0.1,(0.122,0.161))$ & $((0.106,0.119), 0.147,(0.2,0.263))$ \\
\hline $\mathrm{D}$ & $((0.093,0.096), 0.104$ & $((0.088,0.0)$ & $((0.088$ & $, 0.172))$ \\
\hline $\mathrm{E}$ & $((0.106,0.119), 0.147,(0.2,0.263))$ & $((0.096,0.104), 0.119,(0.152,0.2))$ & $((0.088,0.093), 0.1,(0.122,0.161))$ & $((0.116,0.132), 0.167,(0.238,0.357))$ \\
\hline $\mathrm{F}$ & $((0.093,0.098), 0.109,(0.135,0.172))$ & $((0.106,0.119), 0.14$ & $((0.116,0.132), 0$. & $((0.093,0.098), 0.109,(0.1$ \\
\hline G & $((0.083,0.086), 0.089,(0.102,0.128))$ & $((0.083,0.085), 0.086,(0.094,0.111))$ & $((0.083,0.085), 0.086,(0.094,0.111))$ & $((0.088,0.091), 0.096,(0.111,0.135))$ \\
\hline $\mathrm{H}$ & $((0.104,0.114), 0$ & $((0.083,0.0$ & $((0.1)$ & 128)) \\
\hline I & $((0.083,0.086), 0.089,(0.102,0.128))$ & $((0.106,0.119), 0.147,(0.2,0.263))$ & $((0.096,0.104), 0.119,(0.152,0.2))$ & $((0.088,0.091), 0.096,(0.111,0.135))$ \\
\hline $\mathrm{J}$ & $((0.088$ & $((0)$. & )) & 1)) \\
\hline $\mathrm{K}$ & $((0.102,0.111), 0.132,(0.172,0.217))$ & $((0.098,0.104), 0.119,(0.152,0.185))$ & $((0.102,0.111), 0.132,(0.172,0.217))$ & $((0.111,0.122), 0.147,(0.2,0.278))$ \\
\hline $\mathrm{L}$ & $((0.1,0.111), 0.132,(0.172,0.238))$ & $((0.111,0.122), 0.147,(0.2,0.278))$ & $((0.1,0.111), 0.132,(0.172,0.238))$ & $((0.102,0.111), 0.132,(0.172,0$ \\
\hline M & $((0.106,0.119), 0.147,(0.2,0.263))$ & $((0.106,0.119), 0.147,(0.2,0.263))$ & $((0.106,0.119), 0.147,(0.2,0.263))$ & $((0.111,0.128), 0.167,(0.238,0.333))$ \\
\hline $\mathrm{N}$ & $((0.116,0.132), 0.167,(0.238,0.357))$ & $((0.111,0.128), 0.167,(0.238,0.333))$ & $((0.122,0.143), 0.192,(0.294,0.5))$ & $((0.122,0.143), 0.192,(0.294,0.5))$ \\
\hline $\mathrm{O}$ & $((0.152,0.185), 0.278,(0.455,1))$ & $((0.135,0.161), 0.227,(0.385,1))$ & $((0.172,0.217), 0.357,(0.556,1))$ & $((0.152,0.185), 0.278,(0.455,1))$ \\
\hline $\mathrm{P}$ & $((0.1,0.111), 0.132,(0.172,0.238))$ & $((0.096,0.104), 0.119,(0.152,0.2))$ & $((0.096,0.104), 0.119,(0.152,0.2))$ & $((0.1,0.111), 0.132,(0.172,0.238))$ \\
\hline Q & $((0.102,0.111), 0.132,(0.172,0.217))$ & $((0.106,0.119), 0.147,(0.2,0.263))$ & $((0.106,0.119), 0.147,(0.2,0.263))$ & $((0.111,0.128), 0.167,(0.238,0.333))$ \\
\hline $\mathrm{R}$ & $((0.172,0.217), 0.357,(0.556,1))$ & $((0.152,0.185), 0.278,(0.455,1))$ & $((0.172,0.217), 0.357,(0.556,1))$ & $((0.152,0.185), 0.278,(0.455,1))$ \\
\hline
\end{tabular}

The normalized results are weighted by using Eqs (10) and (11). The weighted decision matrix is depicted in Table 11.

Table 11. Weighted decision matrix

\begin{tabular}{|l|c|c|c|c|}
\hline \multirow{2}{*}{} & Probability $\left(\mathrm{O}_{1}\right)$ & Time $\left(\mathrm{O}_{2}\right)$ & & Cost $\left(\mathrm{O}_{3}\right)$ \\
\hline A & $((0.063,0.075), 0.083,(0.093,0.111))$ & $((0.04,0.053), 0.068,(0.087,0.115))$ & $((0.007,0.018), 0.031,(0.045,0.06))$ & $((0.026,0.036), 0.051,(0.071,0.1))$ \\
\hline B & $((0.087,0.116), 0.161,(0.234,0.357))$ & $((0.049,0.069), 0.101,(0.147,0.196))$ & $((0.009,0.028), 0.061,(0.123,0.206))$ & $((0.028,0.039), 0.057,(0.085,0.126))$ \\
\hline C & $((0.096,0.130), 0.186,(0.259,0.357))$ & $((0.054,0.075), 0.113,(0.170,0.25))$ & $((0.007,0.02), 0.037,(0.063,0.099))$ & $((0.034,0.05), 0.083,(0.14,0.206))$ \\
\hline D & $((0.069,0.085), 0.101,(0.120,0.143))$ & $((0.042,0.056), 0.074,(0.094,0.122))$ & $((0.007,0.02), 0.035,(0.057,0.083))$ & $((0.029,0.041), 0.062,(0.095,0.135))$ \\
\hline E & $((0.08,0.105), 0.142,(0.197,0.263))$ & $((0.046,0.064), 0.091,(0.129,0.18))$ & $((0.007,0.02), 0.037,(0.063,0.099))$ & $((0.037,0.055), 0.094,(0.167,0.280))$ \\
\hline
\end{tabular}


End of Table 11

\begin{tabular}{|c|c|c|c|c|}
\hline 壱 & Probability $\left(\mathrm{O}_{1}\right)$ & Time $\left(\mathrm{O}_{2}\right)$ & Cost $\left(\mathrm{O}_{3}\right)$ & Performance $\left(\mathrm{O}_{4}\right)$ \\
\hline $\mathrm{F}$ & $((0.069,0.087), 0.105,(0.133,0.172))$ & $((0.051,0.073), 0.113,(0.17,0.237))$ & $((0.01,0.029), 0.061,(0.123,0.220))$ & $((0.029,0.041), 0.062,(0.095,0.135))$ \\
\hline G & $((0.063,0.076), 0.086,(0.1,0.128))$ & $((0.04,0.052), 0.066,(0.08,0.1))$ & $((0.007,0.018), 0.032,(0.049,0.069))$ & $((0.028,0.038), 0.054,(0.078,0.106))$ \\
\hline $\mathrm{H}$ & $((0.078,0.1), 0.127,(0.170,0.25))$ & $((0.04,0.053), 0.068,(0.087,0.115))$ & $((0.011,0.032), 0.071,(0.152,0.343))$ & $((0.026,0.036), 0.051,(0.071,0.1))$ \\
\hline I & $((0.063,0.076), 0.086,(0.1,0.128))$ & $((0.051,0.073), 0.113,(0.170,0.237))$ & $((0.008,0.023), 0.044,(0.078,0.123))$ & $((0.028,0.038), 0.054,(0.078,0.106))$ \\
\hline $\mathrm{J}$ & $((0.066,0.082), 0.097,(0.120,0.161))$ & $((0.045,0.06), 0.083,(0.115,0.155))$ & $((0.007,0.019), 0.034,(0.057,0.093))$ & $((0.028,0.039), 0.057,(0.085,0.126))$ \\
\hline $\mathrm{K}$ & $((0.077,0.098), 0.127,(0.170,0.217))$ & $((0.047,0.064), 0.091,(0.129,0.167))$ & $((0.009,0.024), 0.048,(0.089,0.134))$ & $((0.035,0.051), 0.083,(0.14,0.218))$ \\
\hline $\mathrm{L}$ & $((0.075,0.098), 0.127,(0.17,0.238))$ & $((0.054,0.075), 0.113,(0.170,0.250))$ & $((0.008,0.024), 0.048,(0.089,0.147))$ & $((0.032,0.046), 0.075,(0.121,0.170))$ \\
\hline M & $((0.08,0.105), 0.142,(0.197,0.263))$ & $((0.051,0.073), 0.113,(0.17,0.237))$ & $((0.009,0.026), 0.054,(0.103,0.162))$ & $((0.035,0.053), 0.094,(0.167,0.261))$ \\
\hline $\mathrm{N}$ & $((0.087,0.116), 0.161,(0.234,0.357))$ & $((0.054,0.079), 0.128,(0.202,0.3))$ & $((0.01,0.031), 0.071,(0.152,0.308))$ & $((0.039,0.06), 0.109,(0.206,0.392))$ \\
\hline $\mathrm{O}$ & $((0.114,0.164), 0.269,(0.447,1))$ & $((0.065,0.099), 0.174,(0.327,0.9))$ & $((0.014,0.047), 0.131,(0.287,0.617))$ & $((0.048,0.077), 0.157,(0.318,0.783))$ \\
\hline $\mathrm{P}$ & $((0.075,0.098), 0.127,(0.170,0.238))$ & $((0.046,0.064), 0.091,(0.129,0.18))$ & $((0.008,0.023), 0.044,(0.078,0.123))$ & $((0.032,0.046), 0.075,(0.121,0.187))$ \\
\hline Q & $((0.077,0.098), 0.127,(0.170,0.217))$ & $((0.051,0.073), 0.113,(0.17,0.237))$ & $((0.009,0.026), 0.054,(0.103,0.162))$ & $((0.035,0.053), 0.094,(0.167,0.261))$ \\
\hline $\mathrm{R}$ & $((0.129,0.192), 0.345,(0.546,1))$ & $((0.073,0.114), 0.213,(0.386,0.9))$ & $((0.014,0.047), 0.131,(0.287,0.617))$ & $((0.048,0.077), 0.157,(0.318,0.783))$ \\
\hline
\end{tabular}

Distance of each risk from ideal solutions is computed by using Eqs. (12) and (13). Results are presented in Table 12.

The index presented in Eq. (14) is used to rank the risks. The results are depicted in Table 13.

Table 12. Distance of each risk from ideal positive and negative solutions

\begin{tabular}{|c|c|c|}
\hline Activity & $d^{+}$ & $d^{-}$ \\
\hline A & 3.756 & 0.259 \\
\hline B & 3.566 & 0.504 \\
\hline C & 3.535 & 0.533 \\
\hline D & 3.711 & 0.313 \\
\hline E & 3.587 & 0.475 \\
\hline F & 3.614 & 0.446 \\
\hline G & 3.750 & 0.267 \\
\hline H & 3.626 & 0.449 \\
\hline I & 3.674 & 0.363 \\
\hline J & 3.702 & 0.328 \\
\hline K & 3.610 & 0.441 \\
\hline L & 3.591 & 0.468 \\
\hline M & 3.542 & 0.532 \\
\hline N & 3.429 & 0.716 \\
\hline O & 3.061 & 1.534 \\
\hline P & 3.623 & 0.427 \\
\hline Q & 3.560 & 0.510 \\
\hline R & 2.986 & 1.584 \\
\hline
\end{tabular}

Table 13. Risk of activities ranked based on probability, time, cost and performance

\begin{tabular}{|c|c|}
\hline Activity & Ranking \\
\hline A & 1 \\
\hline B & 12 \\
\hline C & 15 \\
\hline D & 3 \\
\hline E & 11 \\
\hline F & 8 \\
\hline G & 2 \\
\hline H & 9 \\
\hline I & 5 \\
\hline J & 4 \\
\hline K & 7 \\
\hline L & 10 \\
\hline M & 14 \\
\hline N & 16 \\
\hline O & 17 \\
\hline P & 6 \\
\hline Q & 13 \\
\hline R & 18 \\
\hline
\end{tabular}


Now, mathematical model with IVF data is constructed and the equivalent model is computed. The example is solved using GAMS software (CPU Intel core i7 with 8 GB RAM). Based on result, the first and third paths will be critical and $y$ values for activities is as follows:

$$
\begin{aligned}
& y_{A}=1.5, y_{B}=2, y_{D}=2.5, y_{G}=1.5, y_{K}=0.5, y_{N}=2.5, y_{O}=1, y_{P}=1.5, y_{Q}=0.5, y_{R}=1 \\
& z_{A}=1, z_{D}=1, z_{G}=1 .
\end{aligned}
$$

Finally, the activities are categorized. Figure 4 presents the analysis of project activities. Activities A, D, G, J, M, N, O, P, Q and R are on the critical paths achieved by steps 1 and 3. Project manager needs to pay more attention to these activities. Activities B, E, H, K are on the critical path only in one of the scheduling yielded in steps 1 and 3. Activities C, F, I, L are not on the critical paths in steps 1 and 3, therefore, are placed in green column.

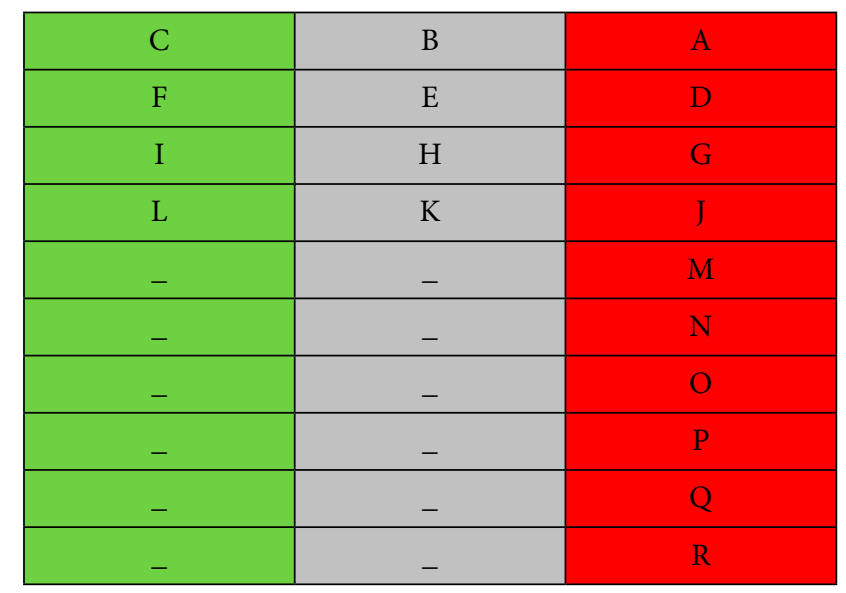

Figure 4. Criticality of project activities

In order to presenting the model's validation, results analysis for some of model's parameters are carried out. First, direct cost per unit time for activities B, D, F, H, J, L, N, P, R are tripled. It is expected that the model selects another activity to crash. The results are shown as below:

$$
y_{A}=1.5, y_{B}=2, y_{D}=2.5, y_{G}=1.5, y_{K}=1, y_{M}=2.5, y_{N}=0.5, y_{O}=1, y_{P}=1.5, y_{Q}=1 .
$$

As it can be seen, crash time of activities $N, R$ are decreased and activities $K, M$ and $Q$ are increased.

In another result analysis, the objective function is calculated for each mode based on different number of non-conformance risks for activities and is expected that for more number of non-conformance risks, objective function value is increased. The results in Table 14 depict expectations.

To demonstrate the accuracy of the results, another result analysis is performed. For the due time specified, different values are considered, and the results are presented in Table 15; it is expected that with increasing due time the objective function reduces. 
Table 14. Objective function value for different number of non-conformance risks for activities

\begin{tabular}{|c|c|c|}
\hline $\begin{array}{c}\text { Number of non-conformance risks } \\
\text { for activities }\end{array}$ & $z_{j}$ & $\begin{array}{c}\text { Objective function value } \\
100 \$\end{array}$ \\
\hline 1 & $z_{A}$ & 154.732 \\
\hline 2 & $z_{A}, z_{G}$ & 389.460 \\
\hline 3 & $z_{A}, z_{G}, z_{D}$ & 483.827 \\
\hline 4 & $z_{A}, z_{G}, z_{D}, z_{J}$ & 587.127 \\
\hline 5 & $z_{A}, z_{G}, z_{D}, z_{J}, z_{I}$ & 611.702 \\
\hline
\end{tabular}

Table 15. Objective function value for different due times

\begin{tabular}{|c|c|c|}
\hline 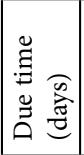 & Crash time for the completion of activity $\mathrm{j}\left(y_{j}\right)$ & $\begin{array}{c}\text { Objective } \\
\text { function } \\
\text { value } \\
100 \$\end{array}$ \\
\hline 18 & $y_{A}=1.5, y_{B}=2, y_{D}=2.5, y_{G}=1.5, y_{K}=1, y_{M}=0.5, y_{N}=2.5, y_{O}=1, y_{P}=1.5, y_{Q}=1, y_{R}=1$ & 516.305 \\
\hline 19 & $y_{A}=1.5, y_{B}=2, y_{D}=2.5, y_{G}=1.5, y_{K}=0.5, y_{N}=2.5, y_{O}=1, y_{P}=1.5, y_{Q}=0.5, y_{R}=1$ & 483.827 \\
\hline 20 & $y_{A}=1.5, y_{B}=2, y_{D}=2.5, y_{G}=1.5, y_{N}=2.5, y_{O}=0.5, y_{P}=1.5, y_{R}=1$ & 454.307 \\
\hline 21 & $y_{A}=1.5, y_{B}=2, y_{D}=2.5, y_{G}=1.5, y_{N}=2, y_{O}=0.5, y_{P}=1.5$ & 426.992 \\
\hline 22 & $y_{A}=1.5, y_{B}=1, y_{D}=2.5, y_{G}=1.5, y_{N}=2, y_{P}=1.5$ & 420.162 \\
\hline
\end{tabular}

Outcomes the results analysis confirm the logical behavior of the proposed model.

\section{Conclusions}

Project scheduling problems (PSPs) is one of the most important subjects in project control. Sometimes top managers and customers do not accept the end time of the project and the contractor must reduce the time of the project. In this paper, a new analytical framework was presented to address time-cost trade-off with considering quality loss cost under interval-valued fuzzy (IVF) uncertainty. First, the developed PERT method was proposed to determine critical path(s) and to identify critical activities. In the next step, for all activities, the nonconformance risks were identified and a multi-criteria group decision-making method was used to identify activities with more risk. Finally, an IVF mixed integer mathematical model for time-cost trade-off problem has been used and an analysis of the activities and routes has been provided. To validate the model, an application of the past studies has been adopted and solved. Achieving a scheduling based on the developed PERT method in the uncertain environment as well as identifying and addressing risks of non-conformance for activities are some of the outcomes of the presented method. Moreover, managing risks based on a new fuzzy group decision approach that considers criteria such as probability, time, cost and performance in addition to scheduling the project while crashing the time of some activities to reach the due time, are some important achievement of this paper. In other words, one of the most essential actions in project management is the identification of activities in terms of criticality. In this paper, the categorizing for activities has been created so as to identify 
project critical activities and to pay more attention to them because if the activities inside the red group are done with delay, the total time of the project would increase. For future studies, improving the framework by developing multi-objective modelling could be an interesting research direction. Moreover, using the concept of critical chain in time crashing could improve the reliability of the scheduling. Furthermore, considering trade-off between delay penalty from total project time and cost of the activity execution time reduction can be added. Finally, other constraints can be added to be model close to impose more considerations based on the real-world.

\section{Acknowledgements}

The authors are grateful to anonymous referees for their insightful comments, which have been helpful in improving the study.

\section{Author contributions}

M. H. Haghighi, S. M. Mousavi and V. Mohagheghi designed the research, analyzed the data and the obtained results as well as developed the paper. J. Antuchevičienè provided extensive advice throughout the study regarding the research design, methodology and findings. All the authors have read and approved the final manuscript.

\section{Disclosure statement}

The authors declare that they have any competing financial, professional, or personal interests from other parties.

\section{References}

Afruzi, E. N., Najafi, A. A., Roghanian, E., \& Mazinani, M. (2014). A multi-objective imperialist competitive algorithm for solving discrete time, cost and quality trade-off problems with mode-identity and resource-constrained situations. Computers \& Operations Research, 50, 80-96.

http://doi.org/10.1016/j.cor.2014.04.003

Ammar, M. A. (2010). Optimization of project time-cost trade-off problem with discounted cash flows. Journal of Construction Engineering and Management, 137(1), 65-71. http://doi.org/10.1061/_ASCE_CO.1943-7862.0000256

Bettemir, Ö. H., \& Birgönül, M. T. (2017). Network analysis algorithm for the solution of discrete timecost trade-off problem. KSCE Journal of Civil Engineering, 21(4), 1047-1058. https://doi.org/10.1007/s10951-007-0031-y

Carlsson, C., \& Fullér, R. (2001). On possibilistic mean value and variance of fuzzy numbers. Fuzzy Sets and Systems, 122(2), 315-326. https://doi.org/10.1016/S0165-0114(00)00043-9

Castro-Lacouture, D., Süer, G. A., Gonzalez-Joaqui, J., \& Yates, J. K. (2009). Construction project scheduling with time, cost, and material restrictions using fuzzy mathematical models and critical path method. Journal of Construction Engineering and Management, 135(10), 1096-1104.

https://doi.org/10.1061/(ASCE)0733-9364(2009)135:10(1096) 
Chen, S. J., \& Chen, S. M. (2008). Fuzzy risk analysis based on measures of similarity between intervalvalued fuzzy numbers. Computers \& Mathematics with Applications, 55(8), 1670-1685. https://doi.org/10.1016/j.camwa.2007.06.022

Chen, S. P., \& Tsai, M. J. (2011). Time-cost trade-off analysis of project networks in fuzzy environments. European Journal of Operational Research, 212(2), 386-397. https://doi.org/10.1016/j.ejor.2011.02.002

Cheng, M. Y., \& Tran, D. H. (2014). Two-phase differential evolution for the multi-objective optimization of time-cost trade-offs in resource-constrained construction projects. IEEE Transactions on Engineering Management, 61(3), 450-461. https://doi.org/10.1109/TEM.2014.2327512

Dahooie, J. H., Zavadskas, E. K., Abolhasani, M., Vanaki, A., \& Turskis, Z. (2018). A novel approach for evaluation of projects using an interval-valued fuzzy Additive Ratio Assessment (ARAS) method: a case study of oil and gas well drilling projects. Symmetry, 10(2), 1-45. https://doi.org/10.3390/sym10020045

Ebrahimnejad, S., Mousavi, S. M., Tavakkoli-Moghaddam, R., \& Heydar, M. (2014). Risk ranking in mega projects by fuzzy compromise approach: A comparative analysis. Journal of Intelligent and Fuzzy Systems, 26(2), 949-959. https://doi.org/10.3233/IFS-130785

El-Sayegh, S. M., \& Al-Haj, R. (2017). A new framework for time-cost trade-off considering float loss impact. Journal of Financial Management of Property and Construction, 22(1), 20-36. http://doi.org/10.1108/JFMPC-02-2016-0007

Foroozesh, N., Tavakkoli-Moghaddam, R., \& Mousavi S. M. (2018). Sustainable-supplier selection for manufacturing services: a new failure mode and effects analysis model based on interval-valued fuzzy group decision-making. International Journal of Advanced Manufacturing Technology, 95(912), 3609-3629. https://doi.org/10.1007/s00170-017-1308-8

Gwak, H. S., Son, S. H., Park, Y. J., \& Lee, D. E. (2016). Exact time-cost trade-off analysis in concurrency-based scheduling. Journal of Construction Engineering and Management, 142(10), 04016054. https://doi.org/10.1061/(ASCE)CO.1943-7862.0001164

Hazır, Ö. (2015). A review of analytical models, approaches and decision support tools in project monitoring and control. International Journal of Project Management, 33(4), 808-815. https://doi.org/10.1016/j.ijproman.2014.09.005

He, Z., He, H., Liu, R., \& Wang, N. (2017). Variable neighbourhood search and tabu search for a discrete time/cost trade-off problem to minimize the maximal cash flow gap. Computers \& Operations Research, 78, 564-577. https://doi.org/10.1016/j.cor.2016.07.013

Hong, D. H., \& Lee, S. (2002). Some algebraic properties and a distance measure for interval-valued fuzzy numbers. Information Sciences, 148(1-4), 1-10. https://doi.org/10.1016/S0020-0255(02)00265-7

Hosseini-Nasab, H., Pourkheradmand, M., \& Shahsavaripour, N. (2017). Solving multi-mode time-costquality trade-off problem in uncertainty condition using a novel genetic algorithm. International Journal of Management and Fuzzy Systems, 3(3), 1-32. https://doi.org/10.11648/j.ijmfs.20170303.11

Ke, H., \& Ma, J. (2014). Modeling project time-cost trade-off in fuzzy random environment. Applied Soft Computing, 19, 80-85. https://doi.org/10.1016/j.asoc.2014.01.040

Kim, J., Kang, C., \& Hwang, I. (2012). A practical approach to project scheduling: considering the potential quality loss cost in the time-cost trade-off problem. International Journal of Project Management, 30(2), 264-272. https://doi.org/10.1016/j.ijproman.2011.05.004

Lee, H. G., Yi, C. Y., \& Lee, D. E. (2015). An advanced stochastic time-cost trade-off analysis based on a cpm-guided genetic algorithm. Computer-Aided Civil and Infrastructure Engineering, 30(10), 824-842. https://doi.org/10.1111/mice.12148

Martin, P., \& Tate, K. (2002). Getting started in project management (Vol. 51). New York: John Wiley \& Sons. 
Meier, C., Yassine, A. A., Browning, T. R., \& Walter, U. (2016). Optimizing time-cost trade-offs in product development projects with a multi-objective evolutionary algorithm. Research in Engineering Design, 27(4), 347-366. https://doi.org/10.1007/s00163-016-0222-7

Mohagheghi, V., Mousavi, S. M., \& Vahdani, B. (2015). A new optimization model for project portfolio selection under interval-valued fuzzy environment. Arabian Journal for Science and Engineering, 40(11), 3351-3361. https://doi.org/10.1007/s13369-015-1779-6

Mohagheghi, V., Mousavi, S. M., \& Vahdani, B. (2016). A new multi-objective optimization approach for sustainable project portfolio selection: a real world application under interval-valued fuzzy environment. Iranian Journal of Fuzzy Systems, 13(6), 41-68. https://doi.org/10.22111/IJFS.2016.2821

Mohagheghi, V., Mousavi, S. M., \& Vahdani, B. (2017). Analyzing project cash flow by a new interval type-2 fuzzy model with an application to construction industry. Neural Computing and Applications, 28, 3393-3411. https://doi.org/10.1007/s00521-016-2235-6

Mohagheghi, V., Mousavi, S. M., Vahdani, B., \& Shahriari, M. R. (2017). R\&D project evaluation and project portfolio selection by a new interval type-2 fuzzy optimization approach. Neural Computing and Applications, 28, 3869-3888. https://doi.org/10.1007/s00521-016-2262-3

Mohagheghi, V., Mousavi, S. M., Vahdani, B., \& Siadat, A. (2017). A mathematical modeling approach for high and new technology-project portfolio selection under uncertain environments. Journal of Intelligent and Fuzzy Systems, 32, 4069-4079. https://doi.org/10.3233/JIFS-152510

Monghasemi, S., Nikoo, M. R., Fasaee, M. A. K., \& Adamowski, J. (2015). A novel multi criteria decision making model for optimizing time-cost-quality trade-off problems in construction projects. Expert systems with applications, 42(6), 3089-3104. http://doi.org/10.1016/j.eswa.2014.11.032

Mousavi, S. M., Tavakkoli-Moghaddam, R., Vahdani, B., Hashemi, H., \& Sanjari, M. J. (2013). A new support vector model-based imperialist competitive algorithm for time estimation in new product development projects. Robotics and Computer-Integrated Manufacturing, 29, 157-168. https://doi.org/10.1016/j.rcim.2012.04.006

Mousavi, S. M., Vahdani, B., \& Abdollahzade, M. (2015). An intelligent model for cost prediction in new product development projects. Journal of Intelligent and Fuzzy Systems, 29(5), 2047-2057. https://doi.org/10.3233/IFS-151682

Mousavi, S. M., Vahdani, B., Tavakkoli-Moghaddam, R., Ebrahimnejad, S., \& Amiri, M. (2013). A multi-stage decision making process for multiple attributes analysis under an interval-valued fuzzy environment. International Journal of Advanced Manufacturing Technology, 64, 1263-1273. https://doi.org/10.1007/s00170-012-4084-5

Orm, M. B., \& Jeunet, J. (2018). Time cost quality trade-off problems: a survey exploring the assessment of quality. Computers \& Industrial Engineering, 118(1), 319-328. https://doi.org/10.1016/j.cie.2018.01.012

Salari, M., Bagherpour, M., \& Reihani, M. H. (2015). A time-cost trade-off model by incorporating fuzzy earned value management: A statistical based approach. Journal of Intelligent \& Fuzzy Systems, 28(4), 1909-1919. https://doi.org/10.3233/IFS-141478

Singh, G., \& Ernst, A. T. (2011). Resource constraint scheduling with a fractional shared resource. Operations Research Letters, 39(5), 363-368. https://doi.org/10.1016/j.orl.2011.06.003

Soltani, A., \& Haji, R. (2007). A project scheduling method based on fuzzy theory. Journal of Industrial and Systems Engineering, 1(1), 70-80.

Tavana, M., Abtahi, A. R., \& Khalili-Damghani, K. (2014). A new multi-objective multi-mode model for solving preemptive time-cost-quality trade-off project scheduling problems. Expert Systems with Applications, 41(4), 1830-1846. https://doi.org/10.1016/j.eswa.2013.08.081

Tran, D. H., Luong, D. L., Duong, M. T., Le, T. N., \& Pham, A. D. (2017). Opposition multiple objective symbiotic organisms search (OMOSOS) for time, cost, quality and work continuity trade-off in repetitive projects. Journal of Computational Design and Engineering, 5(2), 160-172. https://doi.org/10.1016/j.jcde.2017.11.008 
Tseng, M. L., Lim, M., Wu, K. J., Zhou, L., \& Bui, D. T. D. (2018). A novel approach for enhancing green supply chain management using converged interval-valued triangular fuzzy numbers-grey relation analysis. Resources. Conservation and Recycling, 128, 122-133. https://doi.org/10.1016/j.resconrec.2017.01.007

Vahdani, B., Mousavi, S. M., Hashemi, H., Mousakhani, M., \& Ebrahimnejad, S. (2014). A new hybrid model based on least squares support vector machine for project selection problem in construction industry. Arabian Journal for Science and Engineering, 39, 4301-4314. https://doi.org/10.1007/s13369-014-1032-8

Vahdani, B., Mousavi, S. M., \& Ebrahimnejad, S. (2014). Soft computing-based preference selection index method for human resource management. Journal of Intelligent and Fuzzy Systems, 26(1), 393-403. https://doi.org/10.3233/IFS-120748

Wood, D. A. (2017). Gas and oil project time-cost-quality trade-off: Integrated stochastic and fuzzy multi-objective optimization applying a memetic, non-dominated, sorting algorithm. Journal of Natural Gas Science and Engineering, 45, 143-164. https://doi.org/10.1016/j.jngse.2017.04.033

Xu, J., Zheng, H., Zeng, Z., Wu, S., \& Shen, M. (2012). Discrete time-cost-environment trade-off problem for large-scale construction systems with multiple modes under fuzzy uncertainty and its application to Jinping-II Hydroelectric Project. International Journal of Project Management, 30(8), 950-966. https://doi.org/10.1016/j.ijproman.2012.01.019

Yao, J. S., \& Lin, F. T. (2002). Constructing a fuzzy flow-shop sequencing model based on statistical data. International Journal of Approximate Reasoning, 29(3), 215-234. https://doi.org/10.1016/S0888-613X(01)00064-0

Zhang, Z., \& Zhong, X. (2018). Time/resource trade-off in the robust optimization of resource-constraint project scheduling problem under uncertainty. Journal of Industrial and Production Engineering, 35(4), 243-254. https://doi.org/10.1080/21681015.2018.1451400 


\section{APPENDIX}

In the following, preliminary knowledge of IVFSs is presented:

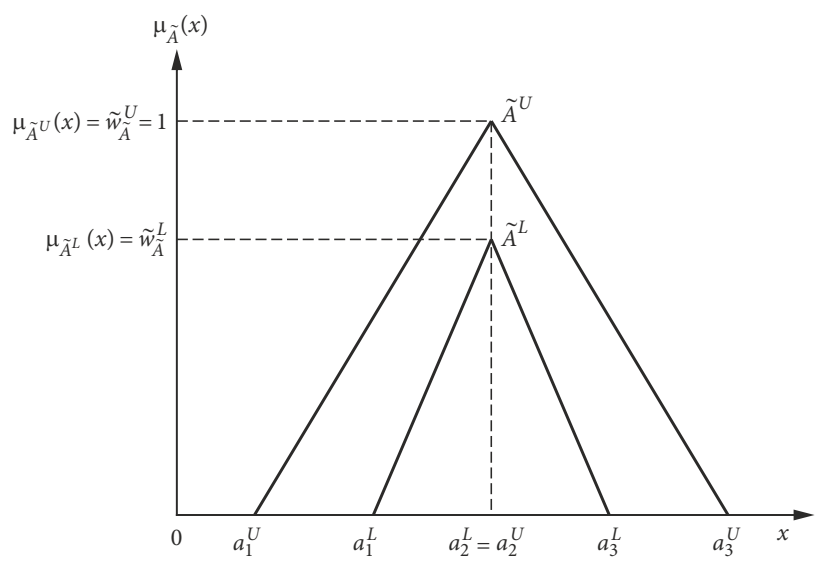

Figure A1. An interval-valued triangular fuzzy number $\widetilde{A}\left(\hat{W}_{\tilde{A}}^{L} \neq \hat{W}_{\widetilde{A}}^{U}\right)$

A triangular interval-valued fuzzy number (shown in Figure A1) is characterized by $\tilde{A}^{L}$ and $\tilde{A}^{U}$ that denote the lower and upper triangular interval-valued fuzzy numbers, and $\hat{W}_{\tilde{A}}^{L}$ and $\hat{W}_{\widetilde{A}}^{U}$ that express the degrees in which an event $x$ could be a part of the lower and upper numbers, respectively (Yao \& Lin, 2002). This number can be depicted as:

$$
\tilde{A}=\left[\tilde{A}_{x}^{L}, \tilde{A}_{x}^{U}\right]=\left[\left(a_{1}^{L}, a_{2}^{L}, a_{3}^{L} ; w_{\tilde{A}}^{L}\right),\left(a_{1}^{U}, a_{2}^{U}, a_{3}^{U} ; w_{\tilde{A}}^{U}\right)\right] .
$$

Operations between two triangular IVF-numbers $\tilde{A}$ and $\tilde{B}$ expressed as $\tilde{A}=\left[\left(a_{1}^{U}, a_{1}^{L}\right), a_{2},\left(a_{3}^{L}, a_{3}^{U}\right)\right]$ and $\tilde{B}=\left[\left(b_{1}^{U}, b_{1}^{L}\right), b_{2},\left(b_{3}^{L}, b_{3}^{U}\right)\right]$, respectively, is presented as follows (Hong \& Lee, 2002; S. J. Chen \& S. M. Chen, 2008):

Addition $\oplus$ :

$$
\begin{aligned}
& \tilde{A} \oplus \tilde{B}=\left[\left(a_{1}^{U}, a_{1}^{L}\right), a_{2},\left(a_{3}^{L}, a_{3}^{U}\right)\right] \oplus\left[\left(b_{1}^{U}, b_{1}^{L}\right), b_{2},\left(b_{3}^{L}, b_{3}^{U}\right)\right]= \\
& {\left[\left(a_{1}^{U}+b_{1}^{U}, a_{1}^{L}+b_{1}^{L}\right), a_{2}+b_{2},\left(a_{3}^{L}+b_{3}^{L}, a_{3}^{U}+b_{3}^{U}\right)\right] .}
\end{aligned}
$$

Subtraction $\ominus$ :

$$
\begin{aligned}
& \tilde{A} \ominus \tilde{B}=\left[\left(a_{1}^{U}, a_{1}^{L}\right), a_{2},\left(a_{3}^{L}, a_{3}^{U}\right)\right] \ominus\left[\left(b_{1}^{U}, b_{1}^{L}\right), b_{2},\left(b_{3}^{L}, b_{3}^{U}\right)\right]= \\
& {\left[\left(a_{1}^{U}-b_{3}^{U}, a_{1}^{L}-b_{3}^{L}\right), a_{2}-b_{2},\left(a_{3}^{L}-b_{1}^{L}, a_{3}^{U}-b_{1}^{U}\right)\right] .}
\end{aligned}
$$

Multiplication $\otimes$ :

$$
\begin{aligned}
& \tilde{A} \otimes \tilde{B}=\left[\left(a_{1}^{U}, a_{1}^{L}\right), a_{2},\left(a_{3}^{L}, a_{3}^{U}\right)\right] \otimes\left[\left(b_{1}^{U}, b_{1}^{L}\right), b_{2},\left(b_{3}^{L}, b_{3}^{U}\right)\right]= \\
& {\left[\left(a_{1}^{U} \times b_{1}^{U}, a_{1}^{L} \times b_{1}^{L}\right), a_{2} \times b_{2},\left(a_{3}^{L} \times b_{3}^{L}, a_{3}^{U} \times b_{3}^{U}\right)\right] .}
\end{aligned}
$$


Generalized division $\oslash$ :

$$
\begin{aligned}
& \tilde{A} \oslash \tilde{B}=\left[\left(a_{1}^{U}, a_{1}^{L}\right), a_{2},\left(a_{3}^{L}, a_{3}^{U}\right)\right] \oslash\left[\left(b_{1}^{U}, b_{1}^{L}\right), b_{2},\left(b_{3}^{L}, b_{3}^{U}\right)\right]= \\
& {\left[\left(a_{1}^{U} \div b_{3}^{U}, a_{1}^{L} \div b_{3}^{L}\right), a_{2} \div b_{2},\left(a_{3}^{L} \div b_{1}^{L}, a_{3}^{U} \div b_{1}^{U}\right)\right],}
\end{aligned}
$$

where $b_{1}^{L}, b_{1}^{U}, b_{3}^{L}, b_{3}^{U}$ are non-zero positive real numbers.

Possibilistic mean value of interval valued numbers is obtained as follows:

$$
E(A)=\int_{0}^{1} \gamma \frac{A_{1}(\gamma)+A_{2}(\gamma)+a_{1}(\gamma)+a_{2}(\gamma)}{2} d_{\gamma}=\frac{E(A)^{U}+E(A)_{L}}{2} .
$$

Where possibilistic mean value of $A^{U}$ and $A_{L}$ are denoted by $E(A)^{U}$ and $E(A)_{L}$ respectively (Carlsson \& Fuller, 2001). Possibilistic mean value and $\gamma$-cut of trilingual interval valued fuzzy number $\tilde{A}=\left[\left(a_{1}^{U}, a_{1}^{L}\right), a_{2},\left(a_{3}^{U}, a_{3}^{L}\right)\right]$ are defined as follows:

$$
\begin{aligned}
& {\left[\tilde{A}_{x}^{L}\right]^{\gamma}=\left[a_{2}^{L}-(1-\gamma) a_{1}^{L}, a_{2}^{L}+(1-\gamma) a_{3}^{L}\right] ;} \\
& {\left[\tilde{A}_{x}^{U}\right]^{\gamma}=\left[a_{2}^{U}-(1-\gamma) a_{1}^{U}, a_{2}^{U}+(1-\gamma) a_{3}^{U}\right] ;} \\
& E(A)=\frac{E\left(A^{U}\right)+E\left(A_{L}\right)}{2}=\frac{a_{2}^{L}+a_{2}^{U}}{2}+\frac{a_{3}^{L}-a_{1}^{L}}{12}+\frac{a_{3}^{U}-a_{1}^{U}}{12} .
\end{aligned}
$$

One of extensions of the classical fuzzy set theory is IVFSs. IVFSs because of considering the uncertainty based on the unique nature of the projects and using intervals instead of crisp values to address membership degrees, have advantages over classical fuzzy sets. These sets in recent years have been used in several studies (e.g., Mousavi, Vahdani, Tavakkoli-Moghaddam, Ebrahimnejad, \& Amiri, 2013; Vahdani, Mousavi, \& Ebrahimnejad, 2014; Foroozesh, Tavakkoli-Moghaddam, \& Mousavi, 2018); also, Mohagheghi, Mousavi, and Vahdani (2015, 2016) and have used these sets in project portfolio selection problem. Moreover, green supply chain management (Tseng, Lim, Wu, Zhou, \& Bui, 2018), multi-criteria analysis for example oil and gas well drilling projects (Dahooie, Zavadskas, Abolhasani, Vanaki, \& Turskis, 2018) are some other applications of these sets. 